\title{
Temporal Interactions in the Cat Visual System. II. Suppressive and Facilitatory Effects in the Lateral Geniculate Nucleus
}

\author{
Sacha B. Nelson \\ Robert Bosch Vision Research Center, The Salk Institute for Biological Studies, San Diego, California 92138, and \\ Department of Biology, University of California at San Diego, La Jolla, California 92093
}

\begin{abstract}
Extracellular responses were recorded from single neurons in the lateral geniculate nucleus (LGN) of the cat during presentation of pairs of brief visual stimuli identical to those that produce orientation-selective paired-pulsed suppression in the visual cortex. LGN neurons also show pairedpulse suppression, but the suppression is not orientation selective, and it occurs only for short interstimulus intervals (ISIs; usually less than $200 \mathrm{msec}$ ). At longer ISIs, most LGN neurons show a period of facilitation. Thus, the paired-pulse suppression in the LGN cannot account for that seen in the visual cortex. Paired-pulse suppression in the LGN was found to be enhanced by stimulation of the receptive field surround. LGN neurons also showed a second type of suppression, termed "offset suppression," which consisted of a more long-lasting suppression of spontaneous activity following the offset of an excitatory visual stimulus. The suppression of spontaneous activity was accompanied by a reduction of the antidromic excitability, assessed by stimulating LGN axons within the cortex or optic radiation. Unlike pairedpulse suppression, offset suppression was not enhanced by increased stimulation of the receptive field surround. Pairedpulse suppression and offset suppression are most likely due to different mechanisms because they have different time courses and depend differently on the spatial properties of the stimuli. Functionally, paired-pulse suppression may be related to the reduced visual sensitivity that accompanies eye movements, while offset suppression may serve to enhance temporal contrast.
\end{abstract}

Presentation of a brief visual stimulus can alter the appearance of a second stimulus presented a short time later. If the 2 stimuli are oriented bars or gratings, the first stimulus can alter the perceived orientation of the second, a phenomenon known as the tilt aftereffect. As described in the previous paper, primary visual cortical neurons in the cat show an orientation-selective suppression that may be related to perceptual phenomena of this kind (Nelson, 1991). Perceptual studies have shown, however, that one stimulus can alter not only the perceived orientation of a second stimulus, but also its visibility. This is called

Received July 5, 1989; revised Aug. 3, 1990; accepted Aug. 30, 1990.

I am grateful to Dr. Simon I eVay for support and advice, to Tom Albright for helpful discussions, and to Kent Allen for technical assistance. This work was supported by NIH Grant EY05551 to Simon LeVay and by Medical Scientist Training Grant PHSGM07198.

Correspondence should be addressed to Sacha Nelson, The Salk Institute for Biological Studies, P.O. Box 85800, San Diego, CA 92138.

Copyright (C) 1991 Society for Neuroscience 0270-6474/91/110357-12\$03.00/0 forward masking. (Backward masking refers to effects the second stimulus may have on the first.) Most commonly, the effects of the masking stimulus are suppressive (for reviews, see Fox, 1978; Breitmeyer, 1980), but facilitatory effects have also been reported (Bachman, 1988). Generally, the time course of both typcs of masking cffects (Brcitmcycr, 1980) is shortcr than the time course of effects on perceived orientation (Harris and Calvert, 1989), and unlike the orientation effects, masking can readily be demonstrated with unoriented stimuli, such as small circles or annuli.

One prominent theory about the function of masking is that it plays an important role in suppressing vision during eye movements, thus bolstering our impression of a stable visual world in the face of the large displacements of the retinal image associated with saccadic eye movements (Breitmeyer, 1980; Judge et al., 1980). Physiological studies of saccadic suppression have shown both in the cat (Noda, 1975) and in the monkey (Bartlett et al., 1976) that, following a saccade, the conduction of visual information through the lateral geniculate nucleus (LGN) is impaired for a period of approximately $100 \mathrm{msec}$. The effect seems to depend largely (Bartlett et al., 1976) or entirely (Noda, 1975) on visual stimulation occurring before and during the saccade and can be mimicked by rapid displacement of a patterned retinal image (Noda, 1975). Following the inhibitory period, geniculate excitability is enhanced (Noda, 1975; Bartlett et al., 1976). A transient inhibition that has a similar time course and is followed by an excitatory rebound has also been recorded intracellularly in LGN neurons after orthodromic or antidromic stimulation (Singer and Creutzfeldt, 1970).

In the studies of saccadic suppression described above, the visual stimulus believed to cause the suppression is rapid movement of the entire visual field. Less is known about physiological forward masking effects of the small flashed stimuli more typically used to excite LGN neurons. In one study, it was found that offset of an excitatory visual stimulus (e.g., a small spot of light in the center of an on-centered cell) suppressed the response to the onset of a second stimulus occurring up to several hundred milliseconds later (Singer and Phillips, 1974). This was attributed primarily to inhibitory interactions between on- and off-centered LGN neurons with overlapping receptive fields ("antagonistic inhibition"), though it was noted that inhibitory interactions between cells of similar center type ("synergistic" or "lateral" inhibition) might serve to enhance the effect. Lateral inhibition between cells of similar center type has also been invoked in several theoretical accounts of psychophysical masking (see Fox, 1978). Thus, 3 functionally different types of inhibition have been suggested to play a role in masking: transient 
inhibition accompanying eye movements and large field displacements, antagonistic inhibition between nearby cells of opposite center type, and lateral inhibition between cells of the same center type.

The aims of this study were 2-fold. The first was to subject geniculate neurons to precisely the same stimuli that produce orientation-selective suppression in the visual cortex in order to determine whether or not that suppression actually arises in the geniculate. The second was to use the paired-pulse paradigm as a tool for studying suppressive influences in the geniculate with the hope of learning more about the underlying circuitry. To this end, the excitability of geniculate neurons was also monitored by stimulating them antidromically from the visual cortex and optic radiations. This served both to identify projection neurons unambiguously and to provide an independent measure of their excitability as a function of prior visual stimulation. The results demonstrate that, following a visual stimulus, I.GN neurons show a profound and long-lasting decrease in antidromic excitability and spontaneous activity. When the activity of the cell is assayed with a second visual stimulus, however, only a brief suppressive period is seen, and it is followed by a period of facilitation. Thus, paired-pulse suppression in the geniculate cannot account for the cortical effect.

\section{Materials and Methods}

Extracellular recordings were obtained from 10 paralyzed, anesthetized adult cats. Details of the anesthesia, surgical preparation, recording techniques, visual stimulation, and data analysis were identical to those employed in the cortical experiments described in an accompanying paper (Nelson, 1991), except as noted below.

In 6 animals, responses were collected to visual stimulation only. In one of these animals, recordings were obtained from cells and fibers in the primary visual cortex and the underlying white matter. In the remaining 5 animals, recordings were obtained from the A laminae of the lateral geniculate nucleus (LGN). Recording sites were chosen so that the receptive fields lay within the central $10^{\circ}$ of the visual field in accordance with the retinotopic mapping studies of Sanderson (1971). In 4 additional animals, cells recorded in the LGN were stimulated both visually and electrically. Histological reconstruction of the recording sites (for methods, see Nelson, 1991) was performed only for the cortical/white matter experiment and for the first of the LGN experiments. In subsequent $L G N$ recordings, changes in eye dominance and receptive field properties were used to estimate the position of the electrode with respect to laminar boundaries in the nucleus. Recordings were made using either lacquer-insulated tungsten electrodes (resistances of 1-5 $\mathrm{M} \Omega$, exposed tip lengths of $5-15 \mu \mathrm{m}$ ) or glass micropipettes filled with $1.5 \mathrm{M} \mathrm{NaCl}$ and broken off to tip diameters of $2-4 \mu \mathrm{m}$.

In one experiment, a relatively fine-tipped tungsten electrode was used to record responses of fibers encountered in the white matter. These responses differed from the more commonly recorded responses (presumed to be from cell bodies) in a number of ways (Hubel, 1960). The action potentials tended to be shorter in duration, giving them a distinctive sound over the audio monitor. Also, advancing the electrode even a few microns frequently resulted in complete loss of the response. In contrast, the amplitude of somatic action potentials typically wax and wane over the course of $20-40 \mu \mathrm{m}$ of electrode movement. Recorded fibers were assumed to be from the LGN if they had concentric, unoriented, and completely monocular receptive fields. Quantitative tests were used to confirm the presence or absence of orientation selectivity in all fibers and cortical neurons recorded.

Visual stimulation and data analysis. Each cell's receptive field was first mapped by hand using small spots of light. Quantitative testing was performed using the stimulus delivery system described in the preceding paper (Nelson, 1991). All stimuli were presented monocularly.

Temporal interaction tests consisted of randomly interleaved trials in which either a single test stimulus or a test stimulus preceded by a condition stimulus was presented. Condition and test stimuli were identical, stationary, high-contrast $(88 \%)$ light or dark bars, vertical in orientation and $8^{\circ}$ in length. The width of the bars was adjusted to be $1^{\circ}$, or the diameter of the receptive field center when it measured less than $1^{\circ}$. The stimuli were each $200 \mathrm{msec}$ in duration and were separated by an interstimulus interval (ISI) that was varied between 50 and $550 \mathrm{msec}$ (or longer in a few cases). Responses were used to construct poststimulus time histograms (PSTHs; 10-msec bins). For the construction of smoothed histograms, the spike train was digitally convolved with a Gaussian filter (10-msec SD). The response measure used in quantifying temporal interactions was the firing rate during the 10-bin period having the greatest number of spikes. Each trial was repeated 10 or 20 times, and the mean response and its standard error were calculated. The temporal interaction index is defined as the ratio of the control response (test stimulus alone) to the test response (test stimulus preceded by condition stimulus). Spontaneous activity (measured at the beginning and end of each test with no stimulus present) was first subtracted from each response. Temporal interaction indices of less than 1.0 indicate suppression, and indices of greater than 1.0 indicate facilitation. A paired, 2-tailed $t$ test was used to determine whether or not observed suppression or facilitation exceeded the $p<0.05$ criterion for significance. In most cells, additional temporal interaction tests were performed in which the spatial features of the condition and test stimuli were altered.

Forty cells were also tested for linearity of spatial summation using a modified null test (Enroth-Cugell and Robson, 1966; So and Shapley, 1981). The stimulus used was a counterphased sinewave grating whose spatial frequency was chosen to be higher than that most preferred by the cell, but still able to evoke a vigorous response. The spatial phase of the grating was adjusted manually while listening to the cell's response over an audio monitor. Cells were classified as linear $(X)$ if they showed a clear null position (phase) and gave no signs of frequency doubling. Cells were classified as nonlinear $(Y)$ if no null position could be found and if there was clear evidence of frequency doubling. In 38 cells, the criteria could be applied unambiguously; the remaining 2 cells were not classified.

Electrical stimulation. Stimulating electrodes consisted of electrolytically sharpened tungsten wires, lacquer-insulated to within $0.5 \mathrm{~mm}$ of their tips. Two electrodes were placed so that their tips lay in the optic radiation at approximate Horsely-Clark coordinates: anterior, 0.5 and 1.5; lateral, 4.5. These electrodes were placed at a depth of 4-5 mm below the pial surface. The depth was then adjusted until the electrically evoked field potential in the LGN was maximal. Two to 4 additional electrodes were inserted approximately $1 \mathrm{~mm}$ below the cortical surface in area 17 just medial to the crest of the lateral gyrus. These electrodes were spaced $1 \mathrm{~mm}$ apart in the anteroposterior dimension between coordinates P2 and P5. Current pulses (1-50 mA, $0.1 \mathrm{msec}$ ) were provided by a Grass D9 stimulator under computer control. Positions of all stimulation sites were verified histologically. At the beginning of the experiment, multiunit ("hash") recordings were obtained from each of the stimulating electrodes. The LGN recording site was then chosen so that the receptive fields of LGN neurons overlapped 1 or more of the composite receptive fields recorded from the cortical stimulating electrodes.

\section{Results}

\section{The time course of facilitation and suppression}

Temporal interactions were studied in 51 LGN neurons and 11 optic radiation fibers. Results obtained from LGN and optic radiation recordings were nearly identical and so are considered together, except as noted below. The most common type of result is illustrated in Figure 1 for an on-centered $X$ cell. The condition and test stimuli were identical 200-msec flashes of a light bar separated by an ISI that was varied between 100 and $600 \mathrm{msec}$ (Fig. $1 B-G$ ). Figure $1 A$ shows the response to the test stimulus presented alone. When the condition stimulus preceded it by only $100 \mathrm{msec}(B)$, the test response was suppressed. At longer ISIs, however, the test response was enhanced by the preceding condition stimulus. The greatest facilitation occurred at an ISI of $300 \mathrm{msec}(D)$.

All but 4 of the neurons studied were tested at a variety of ISIs ranging from 50 to $650 \mathrm{msec}$ (or longer in some cases). Figure 2 illustrates the time courses obtained for 3 different ncurons recorded in the LGN, including the cell for which individual histograms are shown in Figure 1. The responses were chosen to illustrate the fact that cells showing suppressive and 


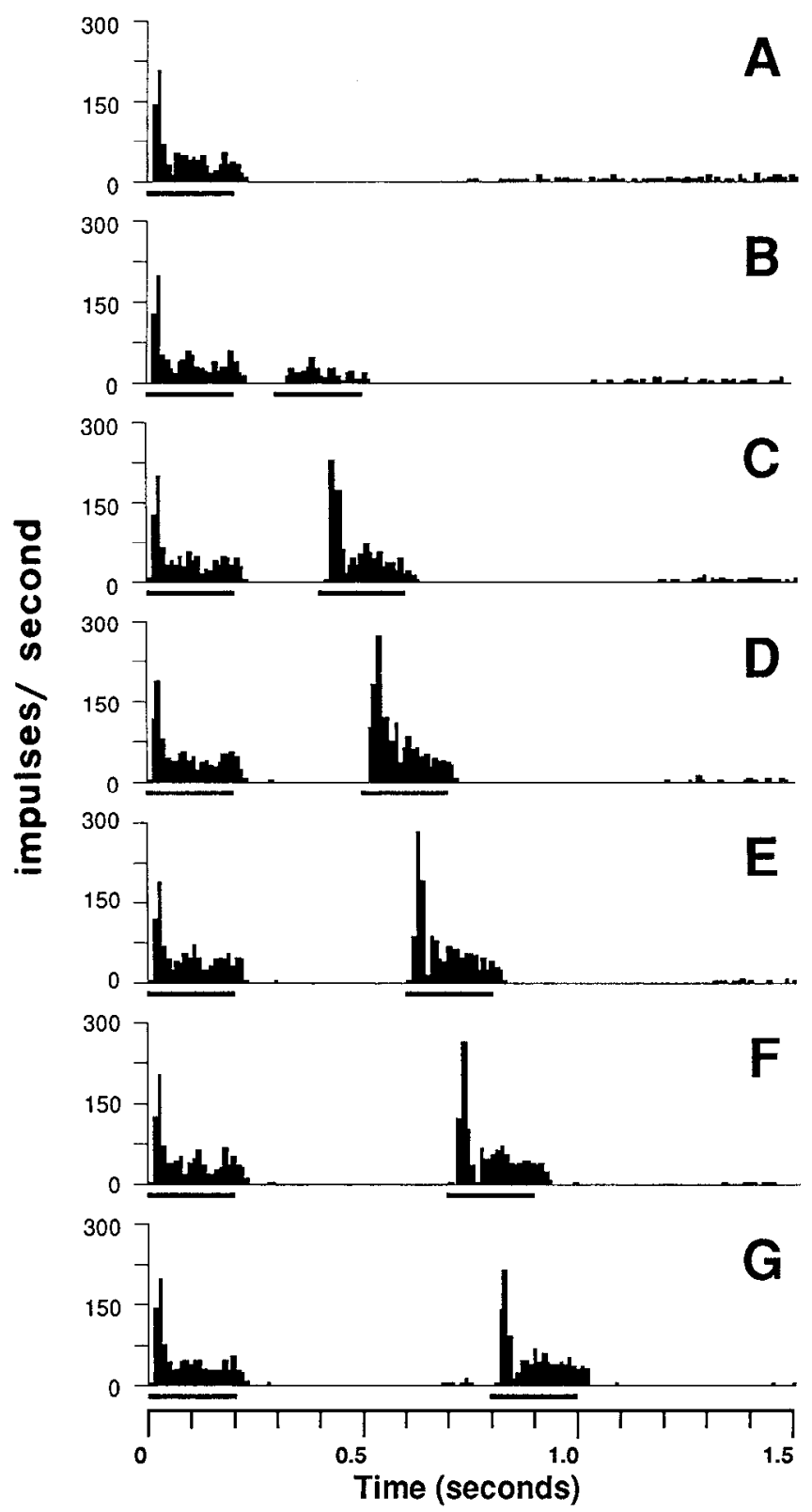

Figure 1. Example of suppressive and facilitatory masking effects observed in LGN neurons. PSTHs show the responses of an on-centered $X$ cell obtained during a temporal interaction test in which both condition and test stimuli were $200-\mathrm{msec}$ flashes of a stationary light bar (indicated by stimulus markers below each histogram) separated by an ISI that was varied between $100(B)$ and $600 \mathrm{msec}(G)$. The response to the test stimulus presented alone is shown in $A$. Histograms were averaged over 20 repetitions. Instantaneous firing rate is indicated on the ordinate. Time in seconds is given at the bottom. Note that, at the shortest ISI tested $(B)$, there is suppression of the test response, but that at longer ISIs $(C-G)$, there is facilitation of the test response. The peak facilitation occurred at an ISI of $300 \mathrm{msec}(D)$.

facilitatory effects formed a continuum. The cell shown in $A$ was an on-centered $X$ cell that showed suppression at ISIs of 50 and $150 \mathrm{msec}$ and no interactions at longer ISIs. The cell shown in $B$ (and in Fig. 1) also showed a brief period of suppression (ISI of $100 \mathrm{msec}$ ), but this was quickly replaced by a longer period of facilitation (200-500 msec). This type of time course was the most common, though for many cells, 1 of the 2 phases (suppressive or facilitatory) failed to reach statistical

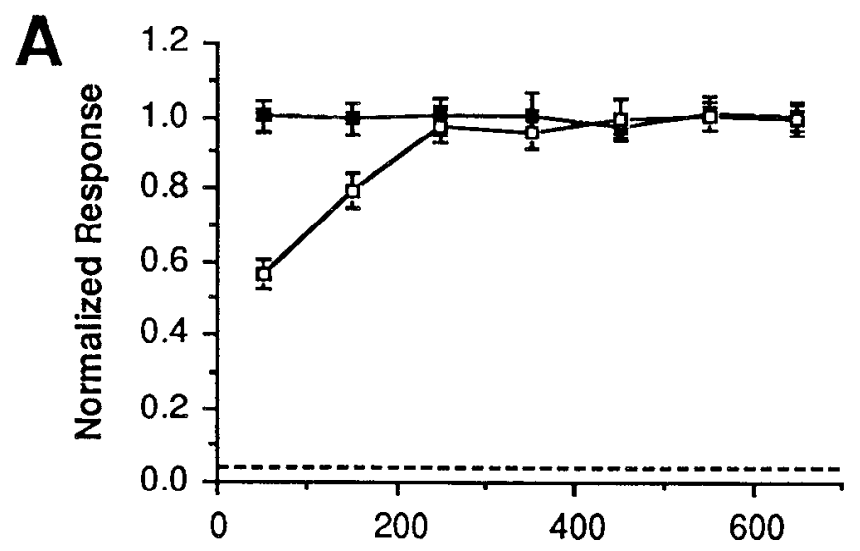

B
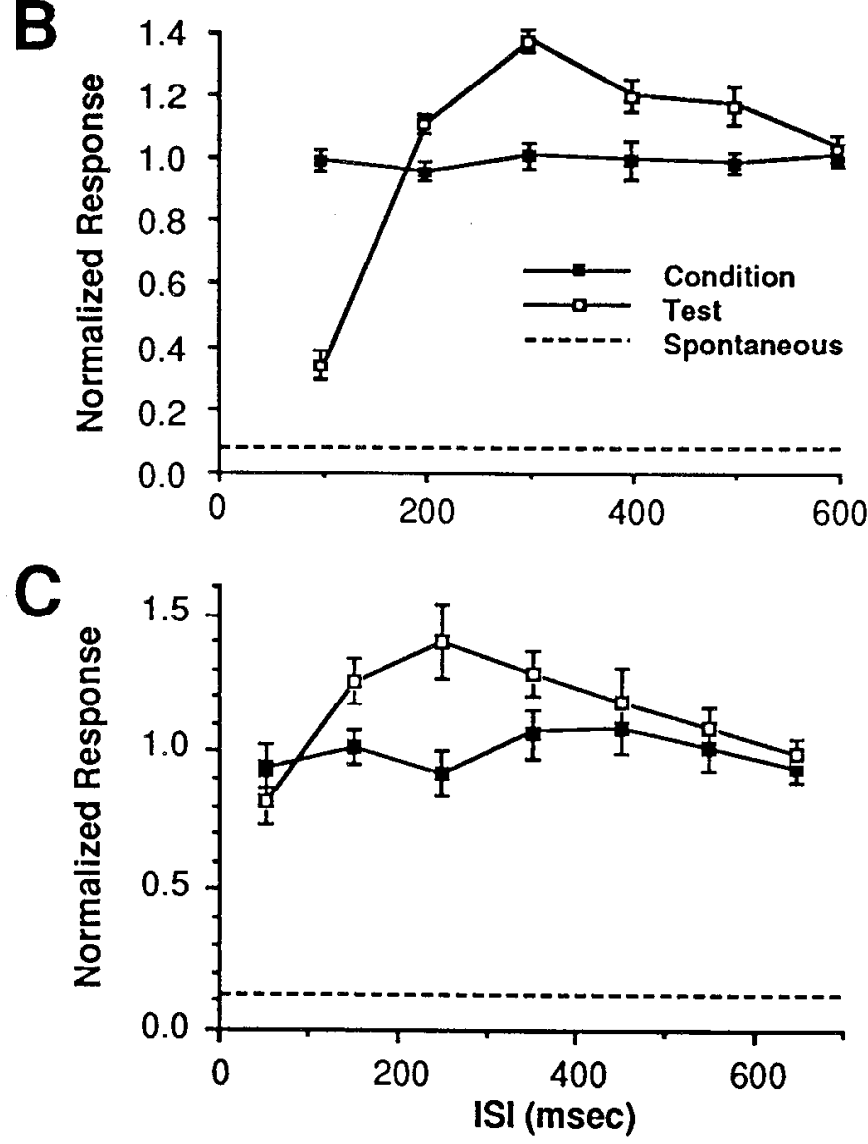

Figure 2. Time course of suppression and facilitation in LGN. Solid squares indicate responses to the condition stimulus. Open squares indicate responses to the test stimulus. Error bars signify SEM over 10 $(C)$ or $20(A, B)$ trials. In each test, responses were normalized to the mean condition stimulus response. Condition and test stimuli were identical light bars. The ISI was varied between 50 and $550(A, C)$ or 100 and $700(B) \mathrm{msec}$. Dashed lines indicate the spontaneous rate. $A$, On-centered $X$ cell that showed suppression at $50-$ and 150 -msec ISIs and no effect at longer ISIs. $B$, The same on-centered $\mathrm{X}$ cell for which individual histograms are shown in Figure 1. $C$, On-centered $Y$ cell that showed no significant effect at $50 \mathrm{msec}$ and facilitation at $150-350 \mathrm{msec}$.

significance (see Materials and Methods). Some cells, like the on-centered $\mathrm{Y}$ cell shown in Figure $2 C$, showed only facilitatory effects. Altogether, of 58 cells tested, 27 showed some period of significant suppression, while 35 cells showed a period of significant facilitation.

Although most cells showed suppression only at short ISIs, 

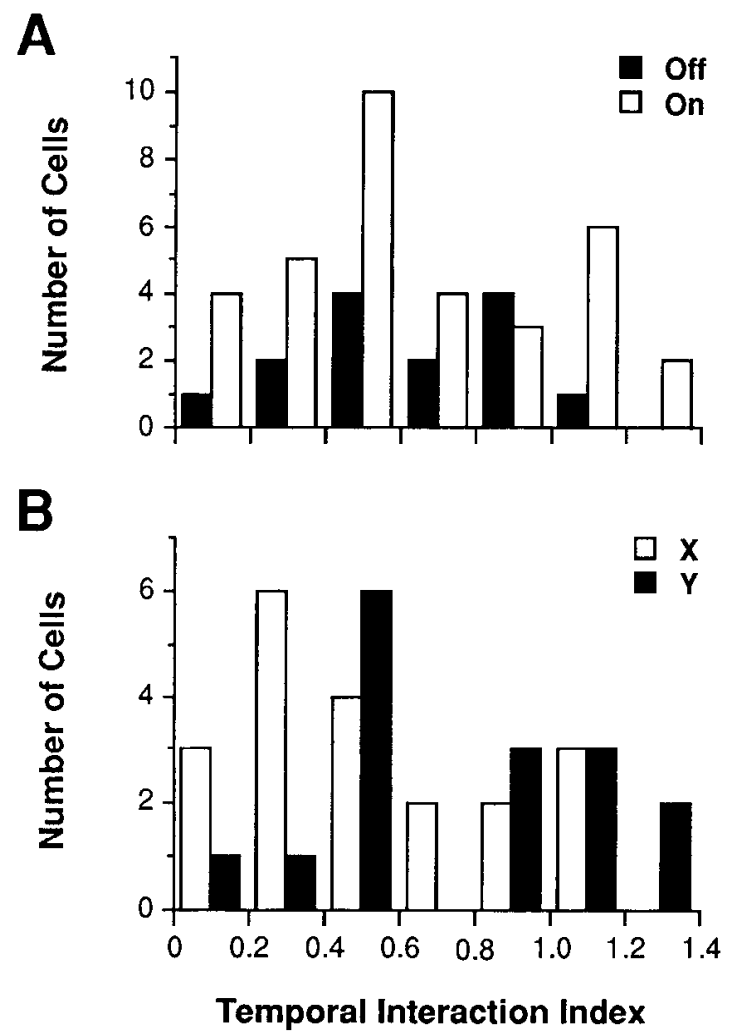

Figure 3. Paired-pulse suppression in different classes of LGN neurons. Temporal interaction indices (see Materials and Methods) were calculated for each cell at a variety of ISIs, and the lowest value obtained was recorded (usually at an ISI of 50 or $100 \mathrm{msec}$ ). $A$, Temporal interaction indices of on- (open bars) and off-centered (solid bars) cells. This histogram includes data from all 34 on-centered neurons stimulated with light bars and 14 off-centered neurons stimulated with dark bars. Data from an additional 14 off-centered neurons stimulated with light bars were excluded. In these latter cells, suppression was weak or absent. $B$, Temporal interaction indices of $\mathrm{X}$ (open bars) and $\mathrm{Y}$ (solid bars) cells. Cells were classified as $\mathrm{X}$ or $\mathrm{Y}$ on the basis of a test for linearity of spatial summation (see Materials and Methods). This histogram includes data from 36 of 40 cells tested that could be unambiguously classified and that were tested with bars of appropriate contrast.

there were a few cells in which the effect was more persistent. The longest ISI at which any cell showed suppression was 400 msec, but this was observed in only 1 cell. Two other cells showed suppression at an ISI of $300 \mathrm{msec}$, and 4 cells showed suppression at an ISI of $200 \mathrm{msec}$. The remaining 51 cells tested either showed suppression only at ISIs of $150 \mathrm{msec}$ or less (20 cells) or showed no significant suppression at any ISI tested (31 cells).

\section{Temporal interactions in different cell types}

Figure 3 shows the incidence of paired-pulse suppression as a function of cell class. For each cell, the value given is the temporal interaction index for the ISI yielding the greatest degree of suppression (usually 50 or $100 \mathrm{msec}$ ). All neurons tested had concentric receptive fields that could easily be classified as on or off centered. Suppression occurred with roughly equal probability among on- and off-centered neurons (Fig. $3 A$ ). Off-centered neurons, however, were more likely to show suppression when tested with dark bars than when tested with light bars. Because of this asymmetry, data from 14 off-centered cells tested only with light bars have been excluded from the summary
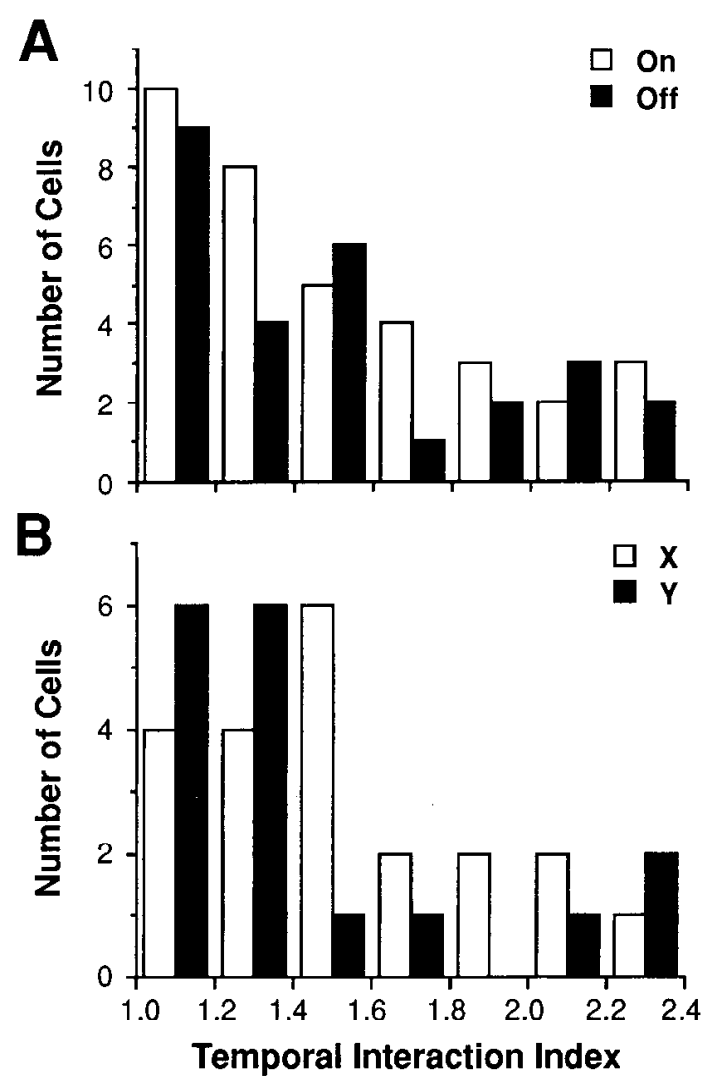

Figure 4. Facilitation in different classes of LGN neurons. Temporal interaction indices (see Materials and Methods) were calculated for each cell at a variety of ISIs, and the highest value obtained was recorded. $A$, Temporal interaction indices of on-(open bars) and off-centered (solid bars) cells. This histogram includes data from all 62 neurons studied because off-centered neurons stimulated with either light or dark bars were equally likely to show facilitation. $B$, Temporal interaction indices of $\mathrm{X}$ (open bars) and $\mathrm{Y}$ (solid bars) cells. Cells were classified as $\mathrm{X}$ or $Y$ on the basis of a test for linearity of spatial summation (see Materials and Methods). This histogram includes data from 38 of 40 cells tested that could be unambiguously classified.

histograms shown in Figure 3. These cells all showed little suppression, regardless of the ISI. A possible reason for the asymmetry is mentioned in the Discussion.

A test for linearity of spatial summation (see Materials and Methods) was performed in 40 cells. Of these, 38 could unambiguously be classified as linear $(\mathrm{X})$ or nonlinear $(\mathrm{Y})$. As shown in Figure $3 B$, X cells tended to show greater suppression than did $\mathrm{Y}$ cells, though this trend was not significant $(0.1<p$ $<0.2 ; t$ test). (Two off-centered Y cells stimulated only with light bars are not included in the histogram.)

Figure 4 shows the incidence of facilitation as a function of cell class. For each cell, the value given is the masking index for the ISI yielding the greatest degree of facilitation. The degree of facilitation was comparable across all cell classes. All cells studied are included because off-center cells showed a comparable degree of facilitation regardless of whether they were stimulated with light or dark bars.

\section{The contribution of geniculate suppression to cortical suppression}

Most cortical neurons show pronounced suppressive effects when tested at an ISI of $200 \mathrm{msec}$ (Nelson, 1991). Figure 5 shows a 


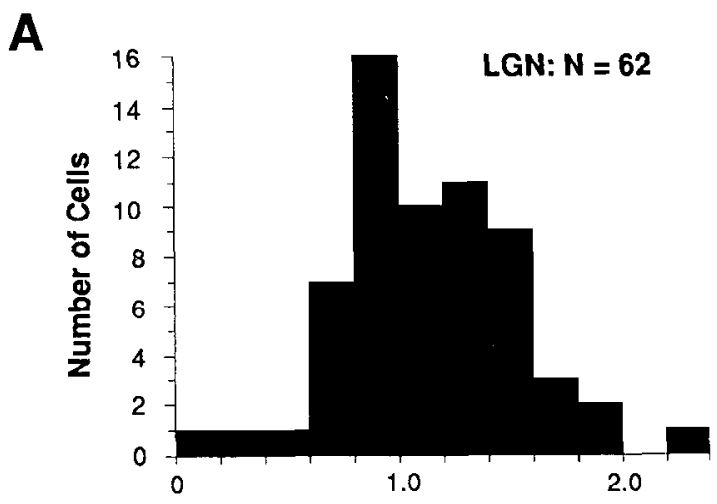

B

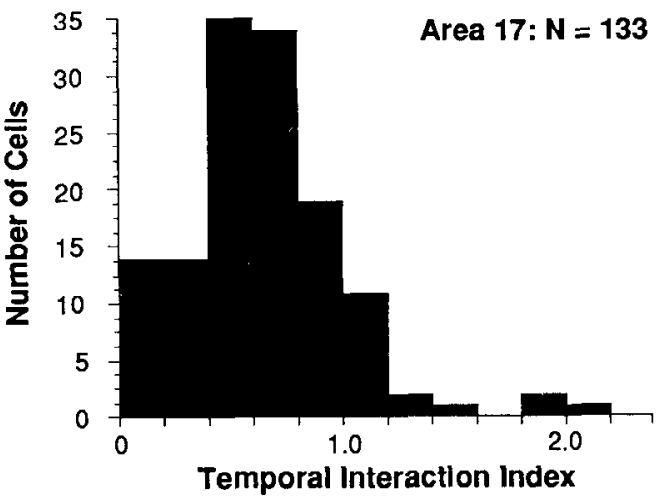

Figure 5. Comparison of paired-pulse suppression in LGN and cortex. All cells were tested at a 200 -msec ISI. $A$, Temporal interaction indices of LGN neurons recorded in the current study. $B$, Temporal interaction indices of area 17 neurons recorded in a previous study. Both samples included a similar proportion (approximately 20\%) of cells in which indices were measured from the offset response to light bars. Note that most LGN neurons show an absence of suppression, and many show facilitation. Most cortical neurons show suppression, and very few show facilitation.

comparison of the temporal interaction effects observed in the LGN in this study (upper histogram) with those observed in the cortex in the preceding study (lower histogram). Both samples contain a similar proportion of cells (roughly $25 \%$ ) for which responses measured were to the offset of a light bar. For most LGN neurons, suppression is over by $200 \mathrm{msec}$, and in fact, many cells showed facilitation at this ISI. In contrast, most cortical neurons continue to show some degree of suppression at $200 \mathrm{msec}$, and many continue to show suppressive effects at much longer intervals (Nelson, 1991).

In order to compare directly the effects seen in LGN projection neurons with those seen in cortical neurons, 2 penetrations were made in which the electrode ran through the thickness of area 17 and into the underlying white matter. Figure 6 illustrates the results obtained from one such penetration. The responses of the cells and fibers encountered are shown as smoothed PSTHs on the right. In the initial descent through the cortical gray matter, an LGN fiber was encountered in layer 4, followed by 2 cortical cells in the deep layers. Six LGN axons and 1 cortical axon were encountered as the electrode passed through the white matter. The latter was easily distinguished from other fiber responses by its well-oriented, binocular receptive field. The responses of 3 more cortical neurons were recorded upon reentering the gray matter toward the end of the penetration. Note that the cortical neurons show varying degrees of suppression, as has been found in previous cortical recordings. In contrast,

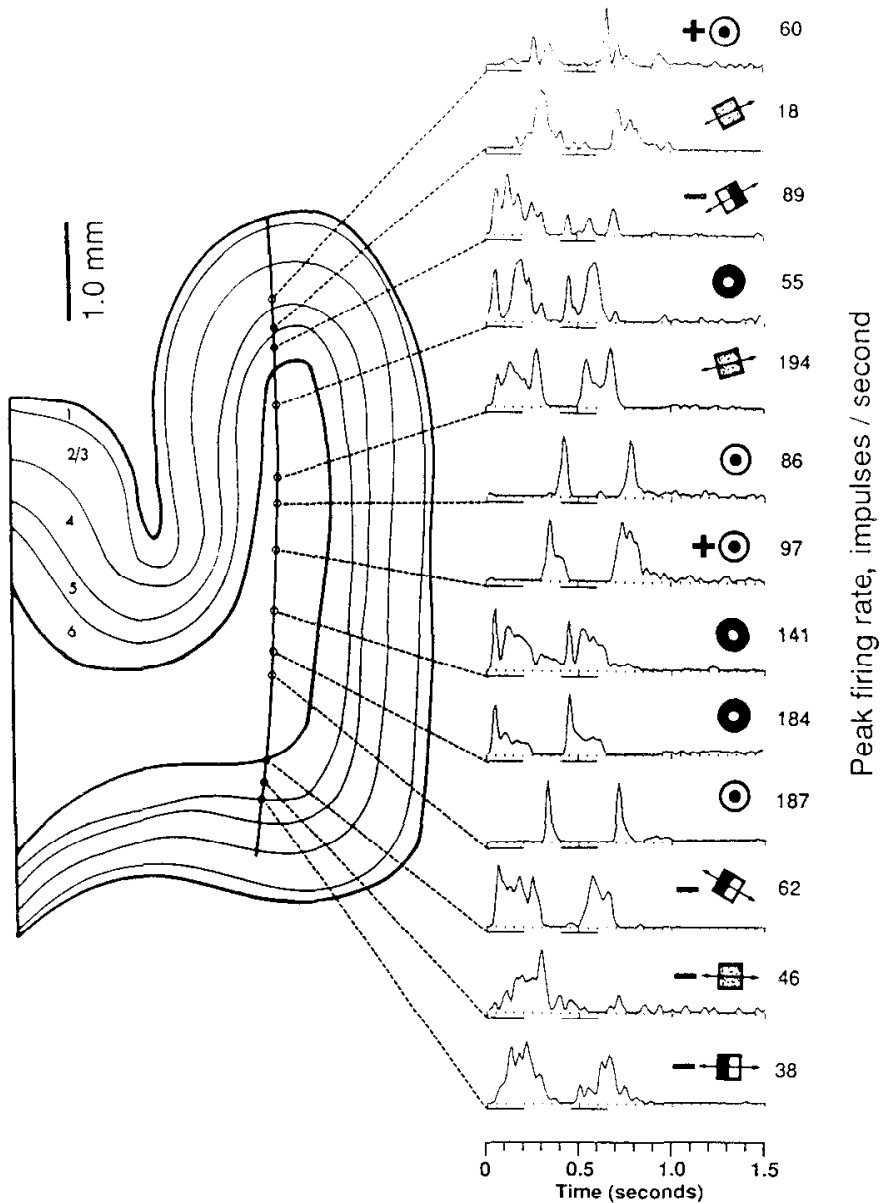

Figure 6. Temporal interaction effects in cells and fibers recorded in cortex and optic radiation. The reconstructed electrode penetration is shown at the left. Laminar boundarics and the location of the electrode track were determined from Nissl-stained sections. Scale bar, $1 \mathrm{~mm}$. Slight curvature of the penetration is probably an artifact from uneven shrinkage during fixation. Responses obtained during standard masking tests are shown on the right. Locations of recorded cells (solid circles) or fibers (open circles) are shown along the electrode track. Responses for each histogram were smoothed and averaged across 20 trials. For each histogram, the maximal response (in impulses/sec) is given along the right-hand margin. Time (in sec) is indicated along the abscissa. Lines below each histogram indicate the duration of condition and test stimuli $(200 \mathrm{msec})$. The symbol in the upper right-hand corner of each histogram indicates the receptive field type: Circles represent concentric, unoriented receptive fields (presumed to correspond to LGN fibers); solid centers indicate off-centered neurons, and open centers indicate on-centered neurons. Squares with arrows indicate oricnted receptivc fields; bipartite squares indicate simple cells, and textured squares indicate complex cells. Plus and minus signs to the left of receptive field symbols indicate statistically significant facilitation and suppression, respectively. Responses of presumed LGN axons were greater in amplitude, showed little or no paired-pulse suppression, and in some cases, showed facilitation. Responses recorded from cortical cells and 1 presumed cortical axon showed varying degrees of suppression but no facilitation.

the LGN fibers encountered showed no temporal interaction effects or, in 2 cases ( 1 st and 7 th histograms), showed facilitation. Similar results were obtained in a second penetration of the same type.

\section{Dependence of paired-pulse suppression on surround stimulation}

The degree of suppression and facilitation evoked by a condition stimulus depended on its size. When temporal interaction tests 

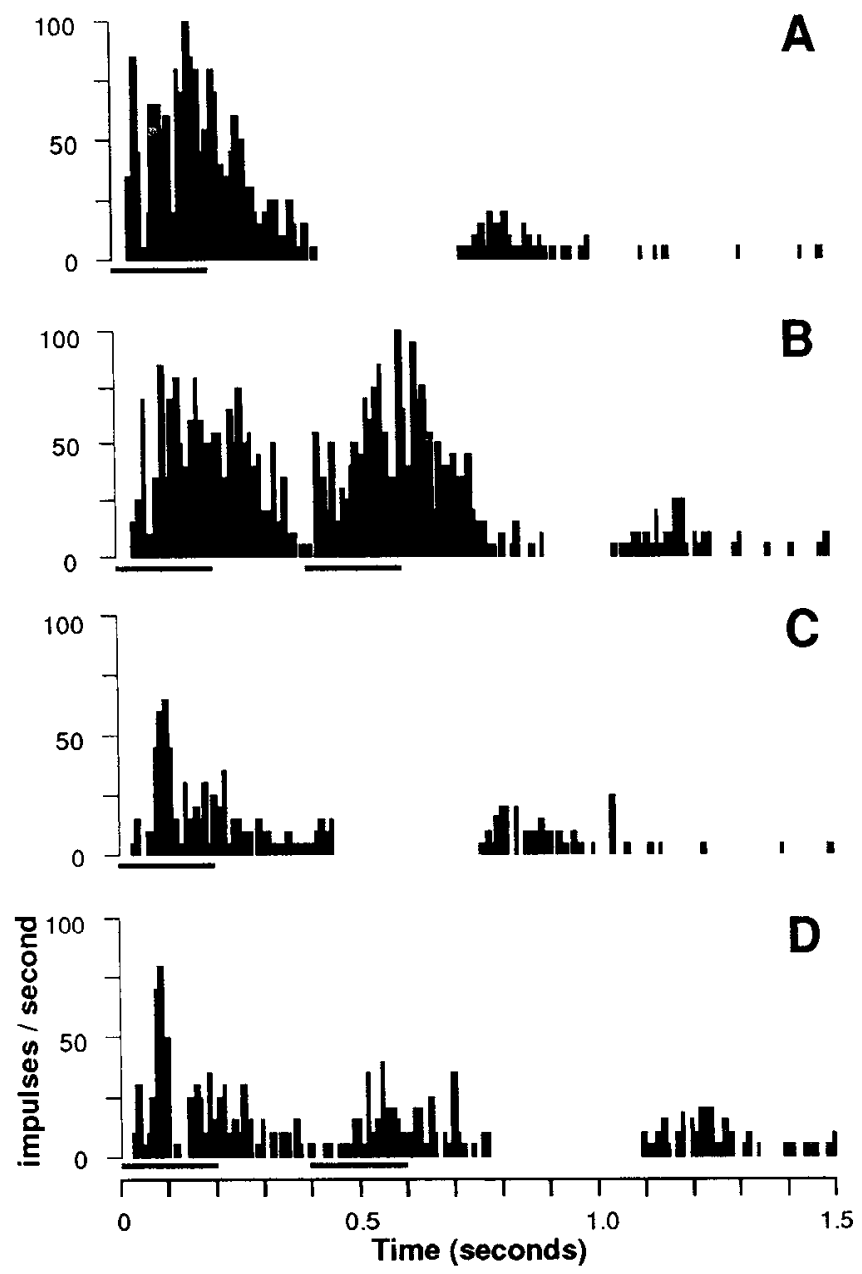

Figure 7. Dependence of paired-pulse suppression on stimulus size. Histograms were obtained from an on-centered X cell during temporal interaction tests in which the condition and test stimuli were both small $\left(0.5^{\circ} \times 0.5^{\circ}\right)$ squares $(A, B)$ or were both elongated $\left(8^{\circ} \times 0.5^{\circ}\right)$ bars $(C$, $D$ ). $A$ and $C$, Responses to test stimulus alone. $B$ and $D$, Responses to condition followed by test. Note that suppression was essentially absent when both stimuli were small squares, but that suppression was present when both stimuli were bars. Stimulus durations were $200 \mathrm{msec}$, and the ISI was $200 \mathrm{msec}$. Other conventions are as in Figure 1.

were performed in which the condition and test stimuli were small squares, confined to the receptive field center, little suppression was seen in most cells, even at very short ISIs. Figure 7 illustrates the differences in the results obtained using small squares and bars for a single on-centered $\mathrm{X}$ cell. This was one of 7 cells that did show significant suppression at an ISI of 200 msec. In the upper 2 histograms (Fig. 7A,B) are shown the results of a temporal interaction test in which both stimuli were small $\left(0.5^{\circ} \times 0.5^{\circ}\right)$ squares. There is little or no effect of the condition stimulus on the response to the test stimulus $200 \mathrm{msec}$ later. The lower 2 histograms (Fig. $7 C, D$ ) show the results obtained when both condition and test stimuli were bars $\left(8^{\circ} \times 0.5^{\circ}\right)$. This cell responded less vigorously to the bars than to the spots, but showed increased paired-pulse suppression.

Figure 8 compares the temporal interaction indices (see Materials and Methods) obtained using small spots with that obtained using larger stimuli for 27 cells. Two types of larger stimuli were used: bars $\left(8^{\circ} \times 0.5^{\circ}\right.$, as described above $)$ and large squares. The squares were adjusted in size so as to be halfway

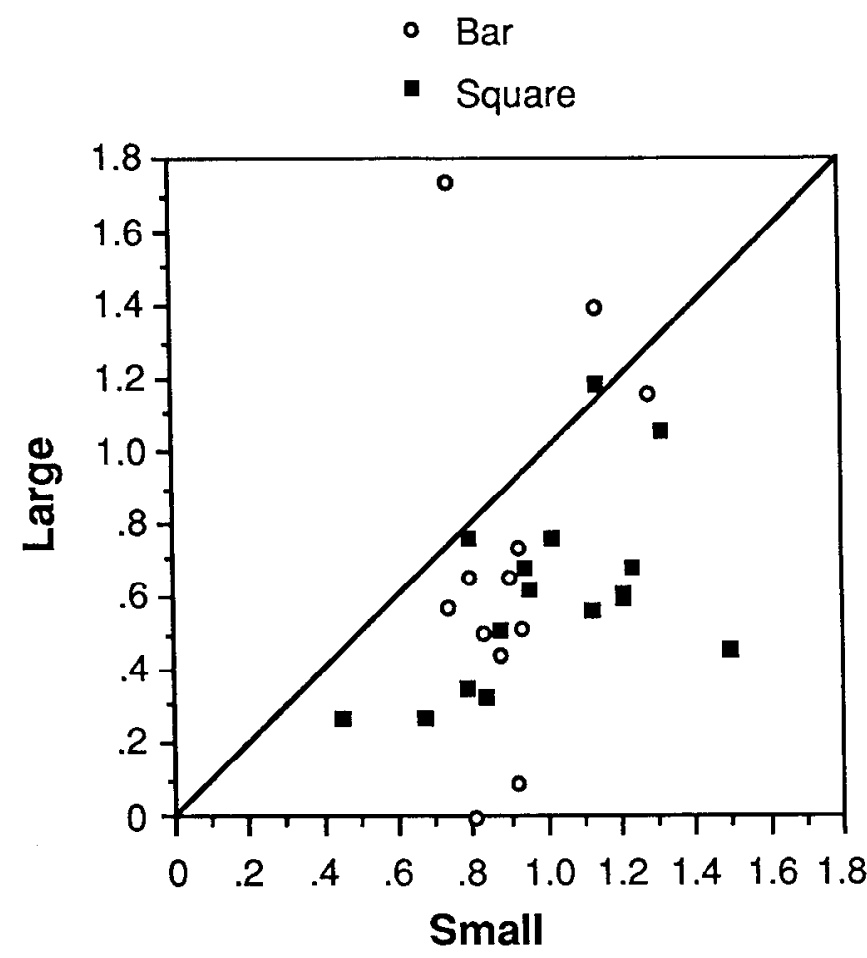

Figure 8. Scatterplot of temporal interaction indices obtained using small and large stimuli. Results are from 27 cells that were subjected to 2 types of temporal interaction tests: one in which condition and test stimuli were both small squares confined to the receptive field center, and a second in which condition and test stimuli were both bars (circles) or squares (squares) that extended well into the receptive field surround. The bars were always $8^{\circ}$ in length. The squares were adjusted in size to produce $50 \%$ of the maximal surround inhibition. Additional tests (not shown) confirmed that suppression produced by a given stimulus was independent of the size of the test stimulus. The diagonal line plots equal suppression with small and large condition stimuli. All but 3 cells had lower indices when tested with large stimuli.

(in length) between the stimulus producing a maximal response and that of the stimulus producing the minimal response (because of surround suppression). In each case, the ISI was 100 msec. In most cells, only minimal suppressive effects could be demonstrated at longer intervals. The diagonal line plots equal suppression in the 2 conditions. All but 3 of the cells had a lower index (i.e., greater suppression) when tested with large stimuli than when tested with small squares. Over the 27 cells tested, the mean temporal interaction index ( \pm SEM) when tested with small stimuli was $95.4 \pm 4.5$, while the mean index when tested with larger stimuli was $65.6 \pm 7.4$. These values were significantly different ( $p<0.01,2$-tailed paired $t$ test). Note that a few cells do show suppression even for small stimuli, but that the suppression is generally much more pronounced for large stimuli. For the data shown, the condition and test stimuli were identical. In 8 cells, the large condition stimulus test was repeated using a small square as the test stimulus. In each case, the degree of masking was independent of the size of the test stimulus.

Paired-pulse suppression in cortical neurons is orientation dependent (Nelson, 1991). LGN neurons have been reported to be biased for orientation (Vidyasagar, 1984). In 12 cells, the possible orientation dependence of suppression was tested using bars of various orientation as the condition stimuli and a bar whose orientation remained constant as the test stimulus. In 8 

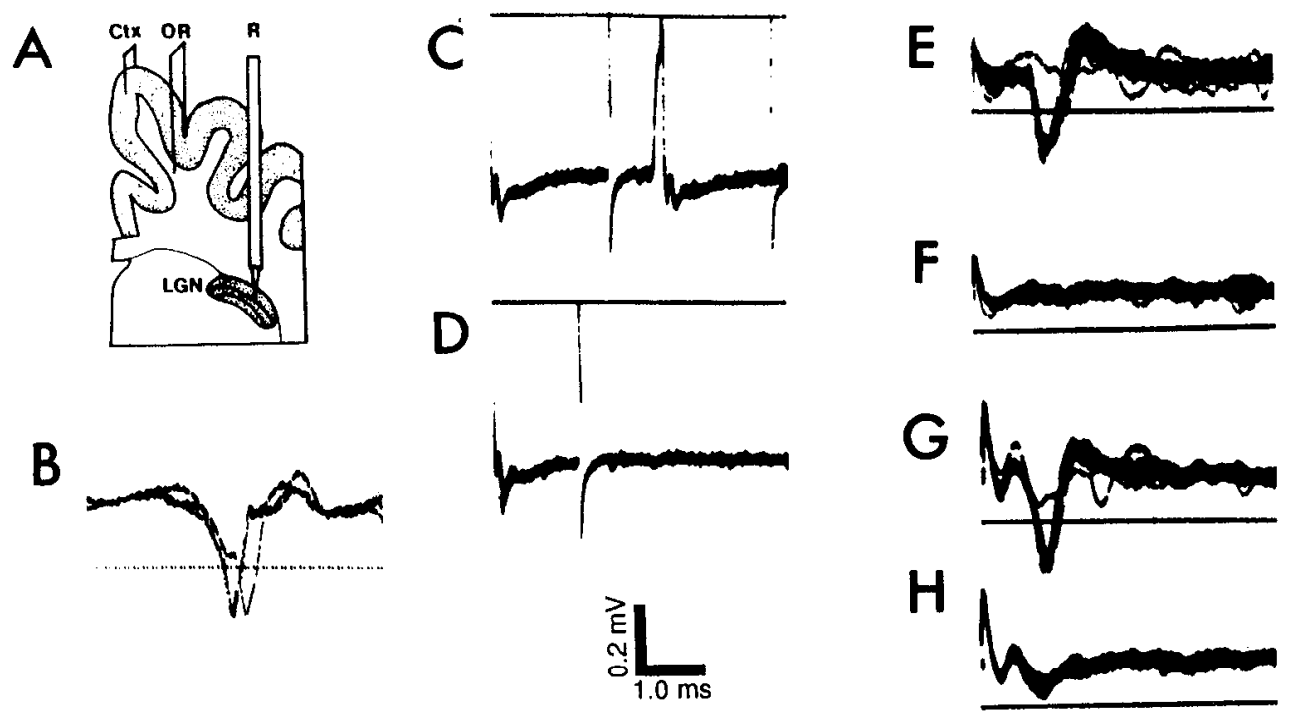

Figure 9. Antidromic stimulation of LGN principal cells. $A$, Diagram of relative positions of stimulating electrodes in the cortex $(C t x)$ and optic radiation $(O R)$ and the recording electrode $(R)$ in the $L G N$. Calibration for all traces $(B-H)$ is $1.0 \mathrm{msec}$ and $0.2 \mathrm{~V} /$ division. $B$, Orthodromically activated neuron: 3 superimposed traces. Note the relatively long and variable latency. $C$ and $D$, Collision test for antidromic activation: 8 superimposed traces, triggered on spontaneously occurring action potentials. The electrical stimulus was delivered to the cortical electrode $(8 \mu \mathrm{A}$, $0.1 \mathrm{msec}$ ) with a delay of $2.0(C)$ or $1.5(D)$ msec. Note the failure to evoke an antidromic action potential after the shorter delay, presumably due to collision with spontaneous action potential. $E$ and $F$, Antidromic activation from the cortex as a function of visual stimulation. This unit responded to a $5-\mu \mathrm{A}$ cortical stimulus with a $60 \%$ probability in the absence of visual stimulation (not shown). One hundred msec after the onset of a visual stimulus confined to the receptive field center, the probability rose to $90 \%(E)$. Two hundred msec following the offset of the visual stimulus, the same cortical shock failed to evoke any antidromic action potentials $(F) . G$ and $H$, Same test as performed in $E$ and $F$, but this time on another cell and with electrical stimulation from the optic radiation. $E-H$ contain 20 superimposed traces each.

of 12 cells, the degree of suppression was independent of the condition stimulus orientation. In the remaining 4 cells, the suppression was greater when the condition and test stimulus orientation were different than when they were the same. This may have been due to the greater degree of surround stimulation that occurred in this case, because condition and test stimuli fell within different, rather than overlapping, parts of the receptive field surround.

\section{Antidromic stimulation}

Both in order to unambiguously identify LGN neurons that project to the cortex, and as an independent means of assessing the suppressive and facilitatory effects of the condition stimulus, 23 cells were stimulated antidromically from the visual cortex or optic radiation at various times during and after a visual stimulus. The placement of stimulating and recording electrodes is indicated schematically in Figure $9 \mathrm{~A}$. Antidromic action potentials (Fig. 9C-H) were distinguished from orthodromically evoked action potentials (Fig. $9 B$ ) by their typically shorter latency, by the constancy of their latency (jitter less than 0.1 $\mathrm{msec}$ ), and by means of the collision test. The latter is illustrated in Figure 9, $C$ and $D$. The electrical stimuli were triggered by the spontaneously occurring action potentials shown at the beginning of each trace. When the stimulus followed the spontaneous action potential with a delay of $2.0 \mathrm{msec}$, a second action potential was evoked. When the delay was shortened to 1.5 msec, however, no second action potential was recorded, presumably because some portion of the axonal membrane was still refractory from the spontaneously occurring action potential. The duration of the period during which a second stimulus failed to elicit an antidromic action potential was only slightly greater than twice the latency $(0.7 \mathrm{msec})$ for this cell.

For all of the LGN neurons tested, the probability of recording an antidromic impulse rose steeply as the stimulus current was increased past a threshold value (range, 4.5-31.3 $\mu \mathrm{A}$; mean, 10.6 \pm 3.0 ), but then plateaued at a probability of less than $100 \%$. This feature of antidromic activation of $L G N$ neurons has been previously described (Bishop et al., 1962). A novel finding of this study, however, is that the probability changed dramatically during the course of visual stimulation. The cell shown in Figure $9, E$ and $F$, for example, could be driven antidromically from the cortex with only a $60 \%$ probability following a $5-\mu \mathrm{A}$ stimulus in the absence of visual stimulation (data not shown). Increasing the stimulating current had little effect, but when the receptive field center was stimulated with a small spot (Fig. $9 E$ ), the probability went up to $90 \%$. Following the offset of the spot, the probability decreased to 0 (Fig. $9 F$ ) and gradually recovered over the next $500 \mathrm{msec}$. Similar results are shown in Figure 9, $G$ and $H$, for another cell that was stimulated from the optic radiation. This general pattern of enhanced antidromic activation during an excitatory visual stimulus and decreased antidromic activation following its offset was seen in all cells tested. Several cells were tested both with light and dark stimuli. Oncentered cells showed decreased antidromic excitability following either the onset of a dark stimulus or the offset of the light stimulus. The reverse was true of off-centered cells.

In 16 cells, the full time course of the effect was investigated by varying the delay between the visual stimulus offset and the electrical pulse. The depression lasted $400 \mathrm{msec}$ or more in 10 cells and lasted between 250 and $400 \mathrm{msec}$ in 5 out of 6 of the remaining cells. Eleven additional cells were tested only at delays of $200 \mathrm{msec}$ or less. Substantial suppression of antidromic excitability was present at $200 \mathrm{msec}$ in 10 of these cells. (The remaining cell showed suppression only for ISIs of $150 \mathrm{msec}$ or less.)

The long-lasting decrease in antidromic excitability was ac- 

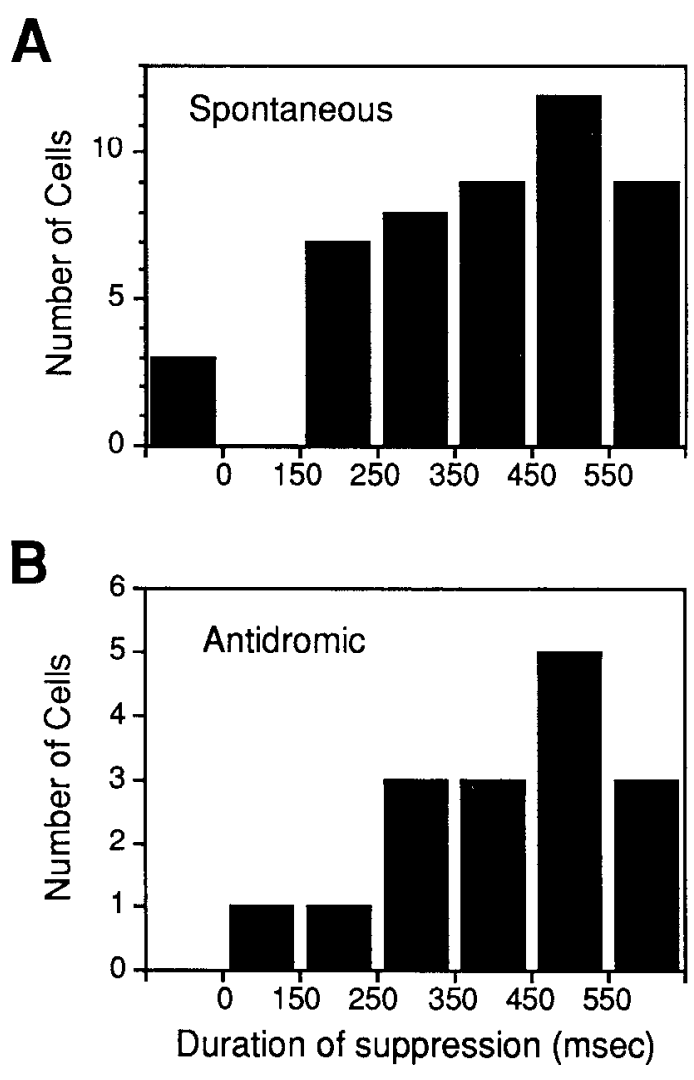

Figure 10. Duration of suppression of spontaneous activity and antidromic excitability following stimulus offset. $A$, Duration of the pause in spontaneous activity seen after offset of an excitatory stimulus (light bar or spot for on-centered cells, dark bar or spot for off-centered cells). Sample includes 48 neurons (the remaining 14 cells in sample were offcentered cells studied only with light stimuli). Durations were measured from stimulus offset to the time at which spontaneous activity returned to the prestimuius rate. Also included were 9 cells that had very low spontaneous activity (making the pause hard to measure) but that did show a pronounced rebound excitation. Three cells in the left-most column showed no detectable pause or rebound excitation. $B$, Duration of suppression of antidromic excitability after visual stimulus offset.

companied in most cells by a pause in spontaneous activity that had a similar time course. The pause in spontaneous activity was also present in most of the cells studied visually but not antidromically. Examples of this pause can be seen in the responses shown in Figures 1 and 7, and in records from previous studies by other workers (see, e.g., Hubel and Wiesel, 1961, their Fig. 1). Typically, the pause lasts between 200 and 500 msec and is followed by a short excitatory burst, which may reflect postinhibitory rebound. Examination of PSTHs from each of the cells studied revealed a pause in spontaneous activity and/or a prominent afterburst in 45 of 48 cells that were studied with stimuli whose sign of contrast matched that of the receptive field center (i.e., light bars for on-centered cells and dark bars for off-centered cells). The duration of the suppression was measured in each cell as the time from stimulus offset until spontaneous activity returned to or exceeded prestimulus levels. In a few cells for which the spontaneous activity was near 0 , the period of suppression was inferred from the presence of a rebound response occurring at about the same time it occurred in other cells. The distribution of durations is shown in Figure $10 A$. Figure $10 B$ shows the distribution of durations of the suppression of antidromic excitability measured in 16 cells. The

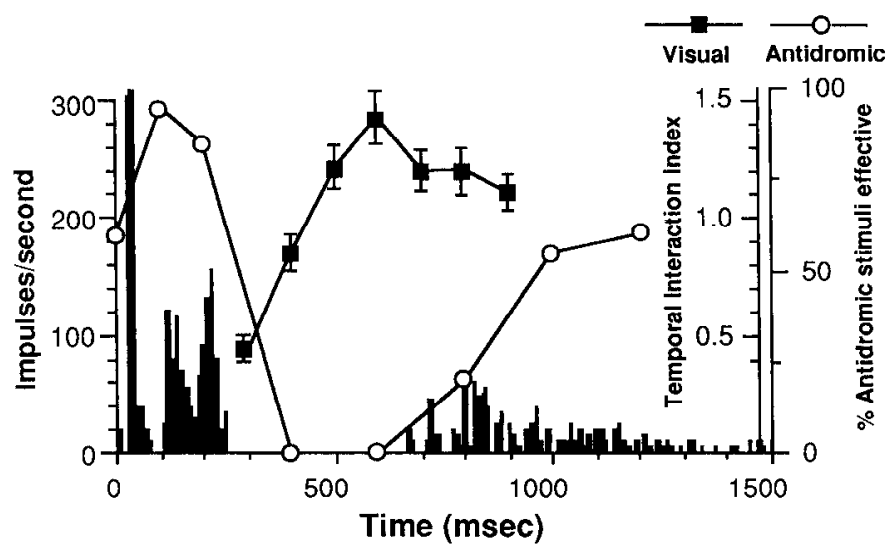

Figure 11. Comparative time course of paired-pulse and offset suppression: 1 of 14 cells in which time course of paired-pulse suppression and of offset suppression were studied concurrently. This PSTH shows the response to a $200-\mathrm{msec}$ condition stimulus $\left(8^{\circ} \times 0.7^{\circ}\right.$ light bar $)$. Offset of the stimulus causes a suppression of spontaneous activity lasting approximately $460 \mathrm{msec}$. Antidromic excitability (open circles) is plotted as the number of action potentials (APs) per 20 shocks (only 1 shock followed each visual stimulus). Excitability rises from 12 APs $(60 \%)$ in the absence of visual stimulation to 20 APs $(100 \%)$ during visual stimulation, then falls to $0 \mathrm{APs}$ shortly after stimulus offset. Recovery was not complete until some time between 600 and $800 \mathrm{msec}$ after stimulus offset. In contrast, paired-pulse suppression (tested with a second visual stimulus identical to the condition stimulus) was over by about $200 \mathrm{msec}$ and was followed by facilitation.

agreement between the duration of the suppression of spontaneous activity and of antidromic activation was true not only for the population, but also for individual cells. In general, the only difference between the time course as measured by spontaneous activity and as measured by antidromic excitability was that the latter did not show a postinhibitory rebound, while the former almost always did. Because the changes in excitability revealed by antidromic activation appeared to have such a different time course from the masking effects, the 2 effects were studied in the same cell in 14 cases. Figure 11 shows the results obtained in one cell. The response of the cell to the masking stimulus (solid histogram) consisted of a vigorous on response followed by a suppression of spontaneous activity upon stimulus offset. The suppression of spontaneous activity lasted approxinlately $450 \mathrm{msec}$ and was followed by a small excitatory rebound. The antidromic excitability of the cell (open circles) showed a remarkably similar pattern with the exception that it did not show a period of postinhibitory rebound. In contrast, the time course of paired-pulse effects (solid squares) was quite different. Paired-pulse suppression was nearly absent by 200 msec after the offset of the condition stimulus (time of $400 \mathrm{msec}$ ) and was followed by a period of facilitation. In each of the 16 cells for which a time course of antidromic excitability was obtained, there was good agreement between the duration of the dip in spontaneous activity seen after the offset of a visual stimulus and the reduction in antidromic excitability. In 13 of 14 cells tested, the time course of the paired-pulse interactions was very different, displaying instead a shortened or absent suppressive period followed in most cases by a facilitatory period. In the remaining cell, the time course of the offset suppression was much shorter $(150 \mathrm{msec})$, and it agreed roughly with the time course of the paired-pulse suppression.

The finding that the 2 types of suppression have different time courses suggests that they may be mediated by different mech- 
anisms. This suggestion was further supported by the finding that, in some cells, the 2 effects could be completely dissociated by changing the spatial configuration of the stimuli. As noted above, paired-pulse suppression occurred preferentially when large stimuli were used. In a few cells, the reverse was true for the suppression of antidromic and spontaneous activation. Results from 1 of 4 such cells studied is shown in Figure 12. The PSTHs indicate the results of temporal interaction tests in which the test stimulus was a small spot and the condition stimulus was either an identical small spot (Fig. 12A) or a large $20^{\circ} \times$ $20^{\circ}$ square $(B)$. The inset oscilloscope traces show the responses evoked antidromically when electrical stimuli were substituted for the visual test stimuli. The small condition stimulus produced only weak suppression of the response to the visual test stimulus, but caused a dramatic suppression of antidromic activation. In contrast, the large stimuli produced substantial paired-pulse suppression (at least at this ISI) but had no effect on the antidromic excitability. The large stimulus, when presented alone (not shown), also produced no excitatory rebound. The excitatory rebound seen in Figure $12 B$ is presumably the result of the small test stimulus. This complete dissociation of the 2 types of suppression was found only in 4 cells. In the remaining cells, the suppression of spontaneous and antidromic activity was present with both large and small stimuli, while the paired-pulse suppression was present only with large stimuli. The implications of these findings for the underlying circuitry generating the 2 types of suppression are discussed below.

\section{Discussion}

The present study has documented the existence of 2 types of suppression that occur in LGN neurons after a brief condition stimulus. The first of these is a suppression of the response to a subsequent visual stimulus, which may be called "paired-pulse suppression." Paired-pulse suppression was present in roughly half the LGN neurons studied, usually lasted less than $200 \mathrm{msec}$, and appeared to be a consequence of stimulation of the receptive field surround by the condition stimulus. The second type is a suppression of spontaneous activity that is accompanied by a reduction in the antidromic excitability of the cell. This type of suppression, which may be called "offset suppression," was present in most of the LGN neurons studied, lasted for $500 \mathrm{msec}$ or more, and did not appear to depend on surround stimulation; in fact, in a few cells, the suppression was absent when large stimuli were employed.

\section{The contribution of the LGN to cortical suppression}

One question addressed by this study was whether or not pairedpulse suppression occurring at the level of the LGN could account for suppression observed in the cortex. The answer seems quite clearly to be no, because the 2 phenomena differed in several important ways. First, they differed in their time course. Cortical suppression usually lasted at least $200 \mathrm{msec}$ and, in some cells, lasted more than $1 \mathrm{sec}$. Geniculate suppression, on the other hand, never lasted more than $400 \mathrm{msec}$ and was, in most cells, absent by $200 \mathrm{msec}$. Most geniculate cells, in fact, showed facilitation at ISIs for which most cortical neurons showed suppression. Second, the orientation dependencies of cortical and geniculate suppression are quite different. Cortical suppression was maximal when the condition and test stimuli were presented at the same (preferred) orientation. Geniculate suppression, on the other hand, was either the same for all combinations of condition and test orientation, or in a few cells,
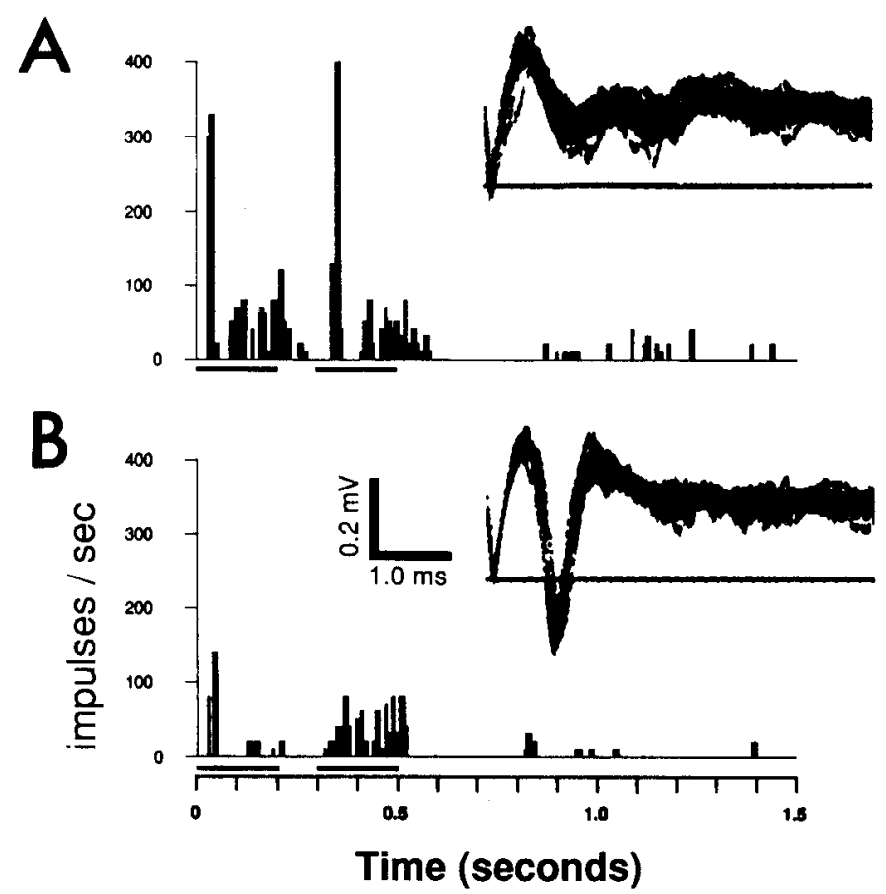

Figure 12. Dissociation of paired-pulse suppression and offset suppression by small versus large condition stimuli. Two temporal interaction tests were performed on the same on-centered Y cell. In both cases, the test stimulus was a small light square confined to the receptive field center. The condition stimulus was either an identical small square $(A)$ or a large $\left(20^{\circ} \times 20^{\circ}\right)$ light square that extended well beyond the boundaries of the receptive field surround. Insets show the antidromic responses obtained in a separate test in which the second visual stimulus was replaced by a shock delivered to the optic radiation. The small condition stimulus produces no suppression of the visual response but profoundly suppresses antidromic excitability. The large condition stimulus causes pronounced visual suppression but has no effect on antidromic excitability. This cell was unusual in that its response to antidromic stimuli was nearly $100 \%$ in the absence of visual stimulation.

was actually greater when the condition and test orientations were different. The reason for this latter pattern of orientation dependence is unclear, but it might be explained by some degree of fatigue in the input to the receptive field surround. If such fatigue occurred, consecutive stimulation of nonoverlapping portions of the surround, as would occur with bars of differing orientation, would cause greater surround inhibition than would repeated stimulation of the same portion of the receptive field surround (as in the case where the condition and test stimuli are identical). Finally, because of the dependence of geniculate suppression on surround stimulation, it was possible in some cells to evoke suppression with wide field stimulation. Such stimuli never produce suppression in the cortex (S. B. Nelson, unpublished observations).

An important question raised by the finding that offset suppression can last for $500 \mathrm{msec}$ or more following a condition stimulus is why this type of suppression does not cause visual suppression with a similar time course. The most straightforward answer is that, though the suppression of spontaneous and electrically evoked activity can persist for several hundred milliseconds in the absence of further visual input, it is immediately truncated by the presence of a second visual stimulus. In a previous study, inhibition occurring at the offset of a small stimulus was found to cause a suppression of the response to a second stimulus (Singer and Phillips, 1974). The discrepancy 
between those results and the present ones is most likely due to a difference in the duration of the stimuli. Singer and Phillips found the most pronounced effects when the first stimulus was $1 \mathrm{sec}$ in duration and the second stimulus was $20 \mathrm{msec}$. Reducing the duration of the first stimulus or lengthening the duration of the second stimulus reduced the effect. Because, in the present study, stimulus duration was not systematically varied, these effects may have gone unnoticed. It should be pointed out that some cells recorded in the present study did show paired-pulse suppression even with small stimuli (see Fig. 8), but the suppression was much weaker than when large stimuli were used.

\section{One suppressive mechanism or 2?}

One interpretation of the different time courses of the 2 types of suppression is that both are due to a single mechanism that is strong enough to cause visual suppression at short ISIs but is weak and/or readily reversed by the presence of a second visual stimulus at longer ISIs. This interpretation is unlikely in light of the observation that the 2 types of suppression depend differently on the size of the masking stimulus. Large stimuli produced stronger paired-pulse suppression, whereas small stimuli were adequate (and in some cells more effective) for causing offset suppression. Instead, it seems more likely that the 2 types of suppression are caused by different mechanisms.

The failure to record antidromic action potentials following the offset of a visual stimulus was presumably due to a failure of antidromic invasion of the cell body, rather than a failure of the cortical shock to initiate an axonal spike. Although changes in terminal excitability have been found to affect the ability to antidromically stimulate other sets of cortical afferents (Takeuchi et al., 1982), this is unlikely to be an explanation for the present results, because the effect could be equally demonstrated using shocks applied to the optic radiation. Previous studies in which antidromic stimulation was combined with intracellular recording (for review, see Lipski, 1981) have suggested that the major reasons for failure of antidromic invasion is the impedance mismatch between the soma and the axonal membrane, and the higher threshold of the soma membrane. The probability of antidromic invasion of the soma is decreased by inhibitory influences that either hyperpolarize the soma or increase conductance without changing the membrane potential. This suggests that, in LGN neurons, the offset of an excitatory visual stimulus produces a long-lasting hyperpolarization and/or inhibitory conductance increase. Hyperpolarization following stimulus offset (or onset in off-centered cells) has been noted in intracellular studies of LGN neurons in vivo (McIlwain and Creutzfeldt, 1967; Singer and Creutzfeldt, 1970; Singer and Phillips, 1974). This inhibitory interaction is believed to be mediated by intrageniculate interneurons that are opposite in center sign to the principal cells they inhibit. This is known as "antagonistic" inhibition, as opposed to "synergistic" or "surround" inhibition that occurs between cells of the same center type (Singer et al., 1972). As is the case with surround inhibition, the basic mechanism of antagonistic inhibition may be present in the retina and enhanced through the action of intrageniculate inhibition. If this is the case (as is suggested by the presence of inhibitory "pauses" in recordings of retinal ganglion cells; see, e.g., Cleland and Lee, 1985, their Fig. 6), then the failure of antidromic invasion seen in this study may result from disfacilitation as well as inhibition. In other words, it may be that the resting membranc potential, and hencc antidromic cxcitability, of LGN neurons reflects a balance between tonic excitatory and inhibitory influences, and that temporary removal of the excitatory retinal input will cause hyperpolarization and a decrease in antidromic excitability even in the absence of an increase in inhibitory drive. Such tonic inhibitory influences might be expected to arise from the fact that inhibitory LGN interneurons receive excitation from ganglion cells and perhaps other LGN neurons, which have some degree of resting discharge.

The spatial dependence of the offset suppression seen in this study is consistent with the idea that it is caused, at least in part, by the feed-forward intrageniculate inhibitory pathway. Unlike cells of the recurrent pathway (perigeniculate neurons), which are reported to respond well only to larger stimuli (Sanderson, 1971; Dubin and Cleland, 1977; So and Shapley, 1981; Xue et al., 1988), the intrageniculate interneurons should be driven maximally by small spots and less vigorously by large stimuli (Dubin and Cleland, 1977). Offset suppression observed in this study was, however, usually as strong for large stimuli as for small. This could reflect a "floor" effect; that is, inhibition with large stimuli is less, but is still sufficient to suppress spontaneous and antidromic excitability to 0 . Alternatively, the inhibition evoked by the offset of large stimuli may be comparable to that evoked by small stimuli either if the surrounds of interneurons are weaker than the surrounds of principal cells, or if larger stimuli stimulate a larger number of interneurons, thus making up for the decreased drive on each one.

The feed-forward and recurrent inhibitory neurons differ not only in their spatial response properties, but also in their temporal response properties. Studies of perigeniculate neurons indicate that they respond transiently and frequently respond equally to stimulus onset and offset (Sanderson, 1971; Dubin and Cleland, 1977; Ahlsén and I indström, 1981; So and Shapley, 1981; Xue et al., 1988). In contrast, intracellular recordings from identified intrageniculate interneurons indicate that they give sustained responses similar in time course to those of sustained projection neurons (Sherman and Friedlander, 1988). This might, as noted above, account for the long time course of the offset suppression observed in this study. Casual comparison of the duration of the suppression with the duration of the firing of off-centered $X$ cells supports this idea.

A second possible reason for the long duration of the offset suppression is that it may be mediated by a postsynaptic response whose time course is long relative to that usually associated with GABAergic inhibition. Several in vitro studies have reported that LGN principal neurons receive not only brief,

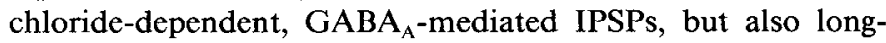
lasting potassium-dependent IPSPs mediated by GABA $_{B}$ receptors (Hirsch and Burnod, 1987; Soltesz et al., 1988). In one study, it was found that a brief orthodromic or antidromic shock to the LGN causes a pause in spontaneous activity that can last hundreds of milliseconds (Hirsch and Burnod, 1987), despite the fact that such a stimulus is unlikely to cause sustained firing of interneurons. Possible contribution of $\mathrm{GABA}_{\mathrm{B}}$ receptors to offset suppression could be studied by in vivo application of the drug phaclofen, which in vitro blocks the late IPSP. It should be noted, however, that evidence favoring a $\mathrm{GABA}_{\mathrm{A}}$-mediated mechanism for antagonistic inhibition has been obtained in a study involving application of the $\mathrm{GABA}_{\mathrm{A}}$ receptor blocker bicuculline (Sillito and Kemp, 1983).

Because the time course of the offset suppression observed in the LGN is similar to that of the paired-pulse suppression seen in the cortex (Nelson, 1991), it might bc hypothesized that the LGN effect is due to cortical feedback acting via inhibitory 
interneurons. If this were the case, however, one would expect that the offset suppression evoked after a second visual stimulus would be far less than the offset suppression evoked after an initial stimulus, because the response of the cortical neuron would be less. As can be observed in Figure 7 (and to some degree in Fig. 1), this is not the case; the "pause" following the offset of a second visual stimulus is as robust as that following a single visual stimulus.

The 2 types of suppression observed in this study differed not only in terms of time course, but also in terms of spatial selectivity. The inhibitory mechanism that produces paired-pulse suppression is more transient and shows a greater degree of spatial summation than that which undcrlics offsct suppression. One attractive hypothesis is that the source of the inhibition responsible for paired-pulse suppression is the perigeniculate neurons. Perigeniculate neurons show a greater degree of spatial summation than do LGN neurons. They typically respond transiently at both the onset and offset of a large stimulus (Ahlsén and Lindström, 1981). Also, intracellular studies have demonstrated that, following electrical stimulation of the cortex or optic radiation, LGN principal cells receive a barrage of IPSPs (mediated at least in part by the perigeniculate nucleus because of the latencies of the earliest IPSPs), which lasts approximately $100 \mathrm{msec}$ and is followed by a postinhibitory rebound (for reviews, see Lindström, 1982; Sherman and Koch, 1986). Perigeniculate neurons are recurrent interneurons in that they are excited by LGN principal neuron axon collaterals. As pointed out by Sherman and Koch (1986), however, it is likely that a given perigeniculate neuron receives most of its excitatory input not from the cell it inhibits, but from nearby cells having slightly displaced receptive fields.

Because perigeniculate neurons typically give on/off responses, it might be expected that paired-pulse suppression should be greatest near both the onset and the offset of the condition stimulus. This was not tested in the present study, but fits the available psychophysical data nicely. Experiments that have measured increment thresholds reveal large threshold elevations near both the onset and the offset of a large condition stimulus (Crawford, 1947). Presumably, inhibition occurring near the onset of an excitatory stimulus is slightly delayed relative to the retinal input and hence does not suppress the initial transient of the excitatory response. Many LGN neurons do, however, show a "notch," or dip in their response immediately after the initial excitatory transient. This is especially evident when large stimuli are used. The idea that inhibition underlying paired-pulse suppression occurs both at stimulus onset and offset, but is delayed relative to excitation, might account for the difference between the results obtained when off-centered neurons were stimulated with dark versus light bars. In the case of a dark bar, the initial response to the condition stimulus will not be subject to inhibition from a preceding onset or offset, but the response to the test stimulus will be modified by inhibition occurring at condition stimulus offset. Hence, the responses to the condition and test stimuli will be different. In the case of a light bar, however, the excitatory response occurs at the offset of the stimulus. Hence, both condition and test responses will be modified by inhibition occurring at stimulus onset, and little difference between the 2 responses should be seen.

\section{Functional implications}

The 2 types of suppression found in this study are best suited to serve different functional roles. As suggested by Singer and colleagues (Singer, 1977), offset suppression probably serves to sharpen the response to successive contrast. It enables an LGN neuron to signal not only the presence of a stimulus within its receptive field, but also the offset of a stimulus within its receptive field during the previous $300-500 \mathrm{msec}$. The fact that the inhibition mediating this suppression is weak and/or readily reversible means that little sacrifice of temporal resolution is required.

In contrast, paired-pulse suppression does reflect a loss of temporal resolution. This may, in fact, be part of its function if, as suggested by Noda (1975), Judge et al. (1980), and others, masking's main role is to suppress visual information during saccadic cyc movements. If this is the case, the facilitatory period that follows suppression in most cells could well represent the postsaccadic enhancement reported in some studies (Noda, 1975; Bartlett et al., 1976). This rebound mechanism would increase the efficiency of transmission though the LGN concurrent with refixating the eyes.

\section{References}

Ahlsén G, Lindström S (1981) Excitation of perigeniculate neurones via axon collaterals of principle cells. Brain Res 236:477-481.

Bachman T (1988) Time course of the subjective contrast enhancement for a second stimulus in successively paired above-threshold transient forms: perceptual retouch instead of forward masking. Vision Res 28:1255-1261.

Bartlett JR, Doty RW, Lee BB, Sakakura H (1976) Influence of saccadic eye movements on geniculostriate excitability in normal monkeys. Exp Brain Res 25:487-509.

Bishop PO, Burke W, Davis R (1962) Single-unit recording from antidromically activated optic radiation neurones. J Physiol (Lond) $162: 432-450$.

Breitmeyer BG (1980) Unmasking visual masking: a look at the "why" behind the veil of the "how." Psychol Rev 87:52-90.

Cleland BG, Lee BB (1985) A comparison of visual responses of cat lateral geniculate nucleus neurones with those of ganglion cells afferent to them. J Physiol (Lond) 369:249-268.

Crawford BH (1947) Visual adaptation in relation to brief conditioning stimuli. Proc R Soc Lond [Biol] 134:283-302.

Dubin MW, Cleland BG (1977) Organization of visual inputs to interneurons of lateral geniculate nucleus of the cat. J Neurophysiol 40: $410-427$.

Enroth-Cugell C, Robson JG (1966) The contrast sensitivity of retinal ganglion cells of the cat. J Physiol (Lond) 258:517-552.

Fox R (1978) Visual masking. In: Handbook of sensory physiology, Vol 8 (Held R, Leibowitz H, Teuber HL, eds), pp 629-649. Berlin: Springer.

Harris JP, Calvert JE (1989) Contrast, spatial frequency and test duration effects on the tilt aftereffect: implications for underlying mechanisms. Vision Res 29:129-135.

Hirsch JC, Burnod Y (1987) A synaptically evoked late hyperpolarization in the rat dorsolateral geniculate neurons in vitro. Nature 23: $457-468$.

Hubel DH (1960) Single unit activity in lateral geniculate body and optic tract of unrestrained cats. J Physiol (Lond) 150:91-104.

Hubel DH, Wiesel TN (1961) Integrative action in the cat's lateral geniculate body. J Physiol (Lond) 155:385-398.

Judge SJ, Wurtz RH, Richmond BJ (1980) Vision during saccadic eye movements. I. Visual interactions in striate cortex. J Neurophysiol 43:1133-1155.

Lindström S (1982) Synaptic organization of inhibitory pathways to principal cells in the lateral geniculate nucleus of the cat. Brain Res 234:447-453.

Lipski J (1981) Antidromic activation of neurones as an analytic tool in the study of the central nervous system. J Neurosei Meth 4:1-32.

McIlwain JT, Creutzfeldt OD (1967) Microelectrode study of synaptic excitation and inhibition in the lateral geniculate nucleus of the cat. J Neurophysiol 30:1-22.

Nelson SB (1991) Temporal interactions in the cat visual system. I. 
Orientation-selective suppression in the visual cortex. J Neurosci 11: $344-356$.

Noda H (1975) Depression in the excitability of relay cells of lateral geniculate nucleus following saccadic eye movements in the cat. J Physiol (Lond) 249:87-102.

Sanderson KJ (1971) The projection of the visual field to the lateral geniculate and medial interlaminar nuclei in the cat. J Comp Neurol 148:101-118.

Sherman SM, Friedlander MJ (1988) Identification of $X$ versus $Y$ properties for interneurons in the A-laminae of the cat's lateral geniculate nucleus. Exp Brain Res 73:384-392.

Sherman SM, Koch C (1986) The control of retinogeniculate transmission in the mammalian latcral geniculate nucleus. Exp Brain Res 63:1-20.

Sillito AM, Kemp JA (1983) The influence of GABAergic inhibitory processes on the receptive field structure of $\mathrm{X}$ and $\mathrm{Y}$ cells in cat dorsa lateral geniculate nucleus (dLGN). Brain Res 277:63-77.

Singer W (1977) Control of thalamic transmission by corticofugal and ascending reticular pathways in the visual system. Physiol Rev 57: $386-420$.

Singer W, Creutzfeldt OD (1970) Reciprocal lateral inhibition of on- and off-center neurones in the lateral geniculate body of the cat. Exp Brain Res 10:311-330.

Singer W, Phillips WA (1974) Function and interaction of on and off transients in vision. II. Neurophysiology. Exp Brain Res 19:507-521.

Singer W, Pöppel E, Creutzfeldt OD (1972) Inhibitory interaction in the cat's lateral geniculate nucleus. Exp Brain Res 14:210-226.

So YT, Shapley R (1981) Spatial tuning of cells in and around lateral geniculate nucleus of the cat: $\mathrm{X}$ and $\mathrm{Y}$ relay cells and perigeniculate interneurons. J Neurophysiol 45:107-120.

Soltesz. I, Haby M, Ieresche N, Crunelli V (1988) The GABA antagonist phaclofen inhibits the late $\mathrm{K}^{+}$-dependent IPSP in cat and rat thalamic and hippocampal neurones. Brain Res 448:351-354.

Takeuchi H, Young SJ, Groves PM (1982) Dopaminergic terminal excitability following arrival of the nerve impulse: the influence of amphetamine and haloperidol. Brain Res 245:47-56.

Vidyasagar TR (1984) Contribution of inhibitory mechanisms to the orientation sensitivity of cat dLGN neurones. Exp Brain Res 55:192195.

Xue JT, Carney T, Ramoa AS, Freeman RD (1988) Binocular interaction in the perigeniculate nucleus of the cat. Exp Brain Res 69:497508 . 